\title{
A Prototype Expert System for the Selection of Road Construction Materials
}

\author{
S. Hassim*, K.T. Teh¹, R. Muniandy¹, H. Omar'1, and A. Hassan² \\ ${ }^{*}$ Civil Engineering Department, Universiti Putra Malaysia, P.O. Box 43400, Serdang, Selangor D.E., Malaysia \\ ${ }^{2}$ Kelantan Public Work Department, P.O. Box 15990, Kota Bharu, Kelantan, Malaysia
}

Received 5 June 2004; accepted 29 January 2006

\begin{abstract}
نعوذج نثام خيير لاغثيار مواد الشاء الشرة
حسيم، تح ، مونيادي ، حسن

الفلاصة: تم تطوير نموذج نظام خبير لاختيار المواد المستخدمة في انشاء الطرق والذي يعتدد على نتائج فريدمان وطرق البقارنات الاحصائية المتعددة. وقد تم جمع النتائج

باستخدام استبيانات جمعت من عدد من الهنتصين في مجال الطرق. وتم تفمين العوامل التي توثر على مواد الرصيف الذاصة بكل موقع في القواعد الهددة للنظام. وقد بنيت

القاعدة المعرفية النظام على نتائج الاختبار الاحصائية وبعد ذلك رتبت ثانية وجمت قبل تطوير النظام . وتم استخدام لغة برمجة الحاسب الالي فيجوال بيسك •, التطوير النظام

بينما حفظت قاعدة البيانات الععرفية في نظام مايكروسوفت اكسس . . . . ويمكن استخدام نهوذج النظام الخبير الذي تم تطويره في محاكاة جزء من القدرة على التفكير المنطقي

المحترف المستند على معرفة خبراء او اختصاصي الرصيف لحل مشاكل اختيار المواد. ويمكن ان يساعد النظام مصهي الطرق في تدسين قدراتهم الههنية في تقييم كل المواد

المتوفرة حتى قبل اجراء الاختبارات البعملية.

الهنرداه الهنتاهية : اختيار الهواد، النظام الخبير، الرصيف، انثاء الطرق.

Abstract: A prototype for an expert system in road construction material selection system, which is based on the outcomes of Friedman and multiple comparisons statistical methods was developed. The outcomes were acquired through questionnaires from selected pavement experts. The factors affecting pavement materials under each particular site condition were incorporated into the specific rules of the system. The system knowledge-base was extracted from the statistical testing outcomes and then rearranged and compiled prior to the development of the system. Visual Basic 6.0 was adopted as the programming tool for development of the system, while the knowledge-base of the separate system was kept in Microsoft Access 2000. The prototype expert system can be used to emulate part of the professional reasoning capabilities based on the knowledge of a pavement expert or a specialist to solve problems on materials selection. The system can help road designers to improve their professional ability to evaluate all available materials even before carrying out any laboratory tests.
\end{abstract}

Keywords: Material selection, Expert system, Pavement, Road construction

\section{Introduction}

A lot of money is spent each year in maintenance and rehabilitation of roads, where most of the road problems are due to fatigue cracking and rutting (Muniandy, et al. 2002). However, a lack of specialized human expertise in pavement design (Goh, 1993) and as a result of inexperienced road design practitioners who lack pavement knowledge and assessment and exposure to some other pavement materials often result in the inappropriate selection of road materials for construction. Moreover, the road design standards of Manual of Pavement Design by Public Works Department of JKR Arahan Teknik 5/85 is not updated or improved consistently (JKR, 1986). Due to the previous distresses experienced, JKR's standard and methodology should be reviewed (Emby and Mustafa,

*Corresponding author’s e-mail: hsalih@eng.upm.edu.my
1996). In view of these problems, a study was undertaken with the aid of Intensified Research in Priority Areas (IRPA) funding to develop a prototype expert system for pavement materials selection in order to assist the pavement designer and contractors in selecting pavement materials alternatives. The system incorporates the properties of soil along with the selected road alignments, where pavement materials are severely over stressed. The type and soil conditions, and expected load repetitions are other parameters found to be indispensable in the formulation of a material selection system for road construction. The material performance and the selection of the appropriate construction materials for the various layers under certain traffic loading, and under different types of terrains such as flat, rolling and mountainous were incorporated as important parameters. Such conditions govern the duration of axle loading on the pavement. 
The objective of this study is to develop a pavement material selection system and to incorporate it into the development of the Road Construction Material Selection System (RC-MSS). The materials selected and positions for a particular site condition were obtained via a questionnaire sent to selected pavement experts. The Friedman Test was adopted to analyze the questionnaire output. Rejected null hypothesis tests were then analyzed using multiple comparisons and ranking for each material under each rejected null hypothesis site condition was done.

An expert system is a computer system that emulates the decision ability of a human expert, which is capable of acting in all aspects like a specialist to provide specialized knowledge to solve problems at the level of a human expert. Figure 1 shows the basic concept of an expert system function. Expert systems today are applied to a variety of fields such as medicine, science, engineering, and business (Omar, 2001).

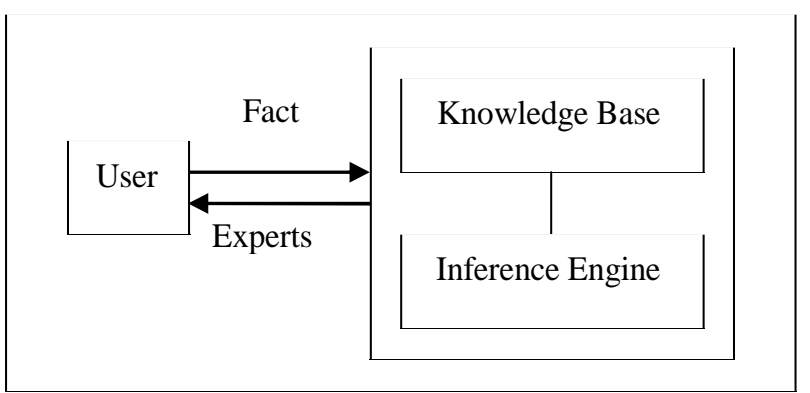

Figure 1. Basic concept of an expert system function layout (Omar, 2001)

\section{Road Construction Material Selection System (RC-MSS) Framework}

The road Construction Material Selection System (RCMSS) was developed based on the survey results obtained from road practitioners, and selected pavement experts. In the surveys to the selected pavement experts, factors and ranges of each category suggested, and ratings were identified each suggested material at each particular site conditions. It is a rating based on the durability, performance and ease of construction at each particular site conditions. Materials rating was then determined using multiple comparisons of each suggested material to see if it is significant to reject null hypothesis of differential in durability, performance and ease of construction in each site condition at 95\% significant level using the Friedman Statistical Test Method. Same position was assigned to the site conditions that it is not significant to reject null hypothesis at 95\% significant level using the Friedman Statistical Test Method. It means that all the materials suggested at that particular site condition have the same performance. The RC-MSS framework was developed before incorporating it in the development of the expert system. Appendix I shows the position of each suggested pavement materials by the experts in site condition 10 of poor soil conditions regardless of traffic loading and the critical area.

\section{Factors Considered in the System}

This study looked into the anticipated traffic loading, soil conditions, type of terrain and geometric features which were considered in the system as the factors in the development of pavement materials selection. Each factor considered in the system was divided into each particular category, which was obtained via documented sources and through interviews with the selected pavement experts. Several interviews were conducted with selected pavement experts to assure that the range of each particular category in each factor is appropriate.

\subsection{Anticipated Traffic Loading Conditions}

Commercial traffic loading was used in the system because pavement starts to deteriorate once it opens to traffic. Failure is caused by heavy axle loads on poor pavement materials. The system incorporates the anticipated Equivalent Single Axle Load (ESAL) as an input factor and it is classified into three categories as illustrated in Table 1.

\section{Table 1. Classification of anticipated ESAL for a 20-} year design life

$\begin{array}{lccc}\begin{array}{l}\text { Traffic } \\ \text { Loading } \\ \text { Anticipated }\end{array} & \text { Low } & \text { Moderate } & \text { High } \\ \text { ESAL } & <300,000 & \begin{array}{c}300,000- \\ 10,000,000\end{array} & >10,000,000 \\ \begin{array}{l}\text { Denoted } \\ \text { Symbol }\end{array} & \text { E1 } & \text { E2 } & \text { E3 }\end{array}$

\subsection{Soil Conditions}

Soil condition is another factor considered in pavement design and materials selection. The strength of a road subgrade is commonly assessed in terms of the California Bearing Ratio (CBR). A higher value of CBR for a soil would be suitable for use as a subgrade. A CBR value of less than $5 \%$ should be considered a poor subgrade soil. The system will use the CBR value as an input data. The data are then classified into three categories as shown in Table 2 (Huang, 1993; Lay, 1990).

Table 2. Soil CBR value divided into three categories

$\begin{array}{lccr}\text { Soil Condition } & \text { Good } & \text { Fair } & \text { Poor } \\ \text { CBR, \% } & >10 & 5-10 & \leq 5 \\ \begin{array}{l}\text { Denoted } \\ \text { Symbol }\end{array} & \text { S1 } & \text { S2 } & \text { S3 }\end{array}$

\subsection{Geometric Features}

Climbing lanes and sharp horizontal curves where multiple heavily loaded vehicles firmly brake, travel at slow speeds or remain standing for periods of time, induce the pavement to deteriorate at a faster rate due to high stresses (Harun, 1992). However, these factors are only considered in geometric design and are less of concern in structural development design. Hence, geometric features 
The Journal of Engineering Research Vol. 4, No.1 (2007) 1-10

such as vertical gradient and degree of horizontal curvature were considered in the system and classified into two categories of critical and non-critical areas as presented in Table 3.

Table 3. Geometric features classification

$\begin{array}{lcc}\begin{array}{l}\text { Geometric Feature } \\ \text { Vertical Gradient }\end{array} & \begin{array}{c}\text { Non-Critical } \\ <5 \%\end{array} & \begin{array}{c}\text { Critical } \\ \geq 5 \%\end{array} \\ \begin{array}{l}\text { Denoted Symbol } \\ \text { (Vertical Gradient) }\end{array} & \mathrm{V} 1 & \mathrm{~V} 2 \\ \begin{array}{l}\text { Degree of } \\ \text { Horizontal Curve }\end{array} & \leq 7^{\circ} & >7^{\circ} \\ \begin{array}{l}\text { Denoted Symbol } \\ \text { (Horizontal Curve) }\end{array} & \mathrm{H} 1 & \mathrm{H} 2\end{array}$

Geometric features of horizontal curvature group and vertical gradient group were regrouped into non-critical areas (assigned symbol is C1) and critical areas (assigned symbol is C2) as presented in Fig. 2. For a non-critical vertical gradient, the degree of vertical gradient measured longitudinally is less than $5 \%$. It is established as a relationship between vertical rise or fall for a unit of horizontal distance. While, a non-critical situation for a horizontal curve is defined as the subtending a 100-foot arc along the curve is less than seven degrees. A critical area means that the area is highly stressed, where multiple heavily loaded vehicles firmly brake, travel at slow speeds or remain standing for periods of time causing the pavement to deteriorate faster.

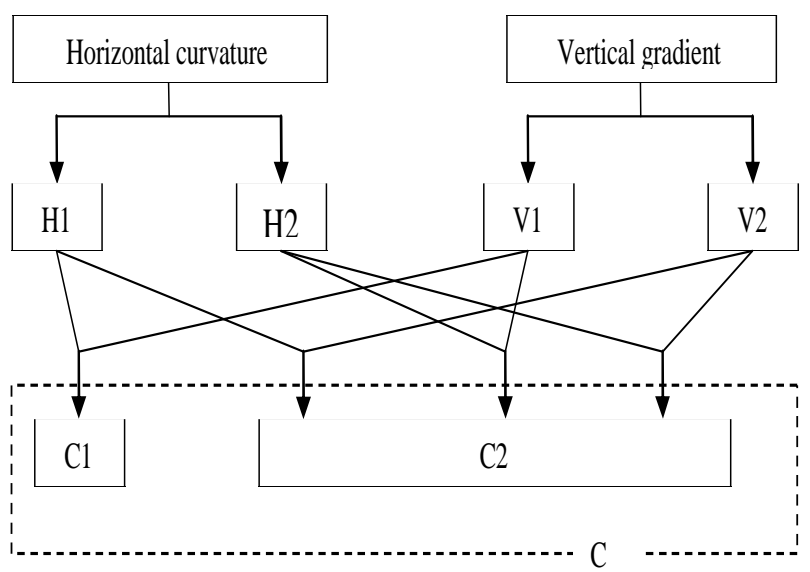

Note: Symbol 'C' denoted as a critical condition

\section{Figure 2. Regrouping of horizontal curvature and vertical gradient groups to critical and non-critical groups}

A real topographic profile such as type of terrain is crucial in pavement design and it is generally divided into three groups: flat, rolling and mountainous which is determined by the percentage of longitudinal slope, as shown in Table 4 (JKR, 1986). The terrain type is incorporated into the system to determine the type of material suitable for the stretch.

Table 4. Terrain type

\begin{tabular}{lccc} 
& \multicolumn{3}{c}{ Type of Terrain } \\
& Flat & Rolling & Mountainous \\
Cross Slope & $\leq 3 \%$ & $3-25 \%$ & $\geq 25 \%$ \\
$\begin{array}{l}\text { Denoted } \\
\text { Symbol }\end{array}$ & $\mathrm{T} 1$ & $\mathrm{~T} 2$ & $\mathrm{~T} 3$
\end{tabular}

\section{System Database and Denoted Symbols}

From the questionnaire given to the pavement experts, the ranges of each factor in each category were divided into 11 design conditions as shown in Table 5. The 11 design conditions were given designated symbols. The database for design condition '0', was obtained via a documented source. Design condition '10' is used for poor soil conditions and is considered critical regardless of the anticipated ESAL and geometric features. Each design condition is then separated into three more conditions for flat, rolling and mountainous terrains, resulting in a total of 33 site conditions.

The RC-MSS framework is shown in Fig. 3. Design conditions consisted of anticipated ESAL group (denoted as E), soil CBR group (denoted as S) and critical area group (denoted as $\mathrm{C}$ ) as shown in Fig. 3. These design conditions would then follow the path indicated by the symbol E, S, C to M. Design conditions consisting of symbol S3 (poor soil group), will go to the next station of a treated subgrade (TSG block), which is the adopted measure for poor soils. Poor soils need to be treated before proceeding to the next step. The modified design conditions after TSG would be considered equivalent to a good soil group as denoted by the symbol S1 before proceeding to the $\mathrm{C}$ group to reach materials suggested database denoted as $\mathrm{M}$. If the previous design condition of symbol designated as TSG block, the database to reach is "Material Suggested Database" with asterisk (denoted symbol is ' $\mathrm{M}^{*}$ ). Block symbol TSG was extracted from design condition '10'. The database of ' $\mathrm{M}^{*}$ ' has the same suggested pavement materials for subbase, base course and surface course as database of $M$ except for the subgrade where ' $\mathrm{M}^{*}$ ' adopted the material from block symbol TSG.

\section{Example Problem}

A simple example was run to illustrate the framework of RC-MSS. The site conditions were as follows.:

Site conditions:

- Anticipated ESAL

- Soil CBR

- Vertical gradient

- Horizontal curvature

- $\quad$ Type of terrain

$$
\begin{aligned}
&= 12,500,000 \text { of } 18 \mathrm{kip} \\
& \quad \text { axle repetitions } \\
&= 3 \% \\
&= 3 \% \\
&= 8^{\circ} \\
&= \text { Flat }
\end{aligned}
$$


Table 5. Designed site conditions and denoted symbols

Soil

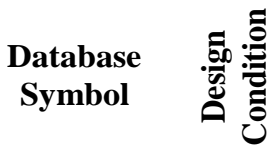

M1

M1*

M2

M2*

M3

M4

M5

M5*

M6

M6*

M7

M7*

M8

M9

M10

TSG

\section{Good}

Good

Fair

Poor

Poor

Good

Poor

Fair

Fair

Good

Poor

Good

Poor

Good

Poor

Fair

Fair

Fair

Poor
Anticipated ESAL

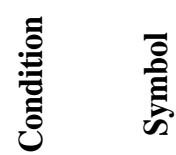

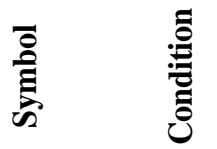

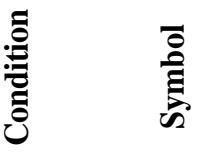

Low

Moderate

Low

Low

Moderate

High

High

Moderate

High

Low

Low

Moderate

Moderate

High

High

Low

Moderate

High

\section{Geometric Features}

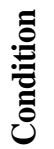

率

Non-critical area

Non-critical

Non-critical

Non-critical area

Non-critical

Non-critical area

Non-critical area

Non-critical area

Non-critical area

Critical area

Critical area

Critical area

Critical area

Critical area

Critical area

Critical area

Critical area

Critical area
C1

C1

C1

C1

C1

C1

C1

C1

C1

C2

$\mathrm{C} 2$

$\mathrm{C} 2$

$\mathrm{C} 2$

C2

C2

C2

$\mathrm{C} 2$

$\mathrm{C} 2$

Note: 1. *Poor soil condition

2. Dense-graded mix will remain the same for a binder course

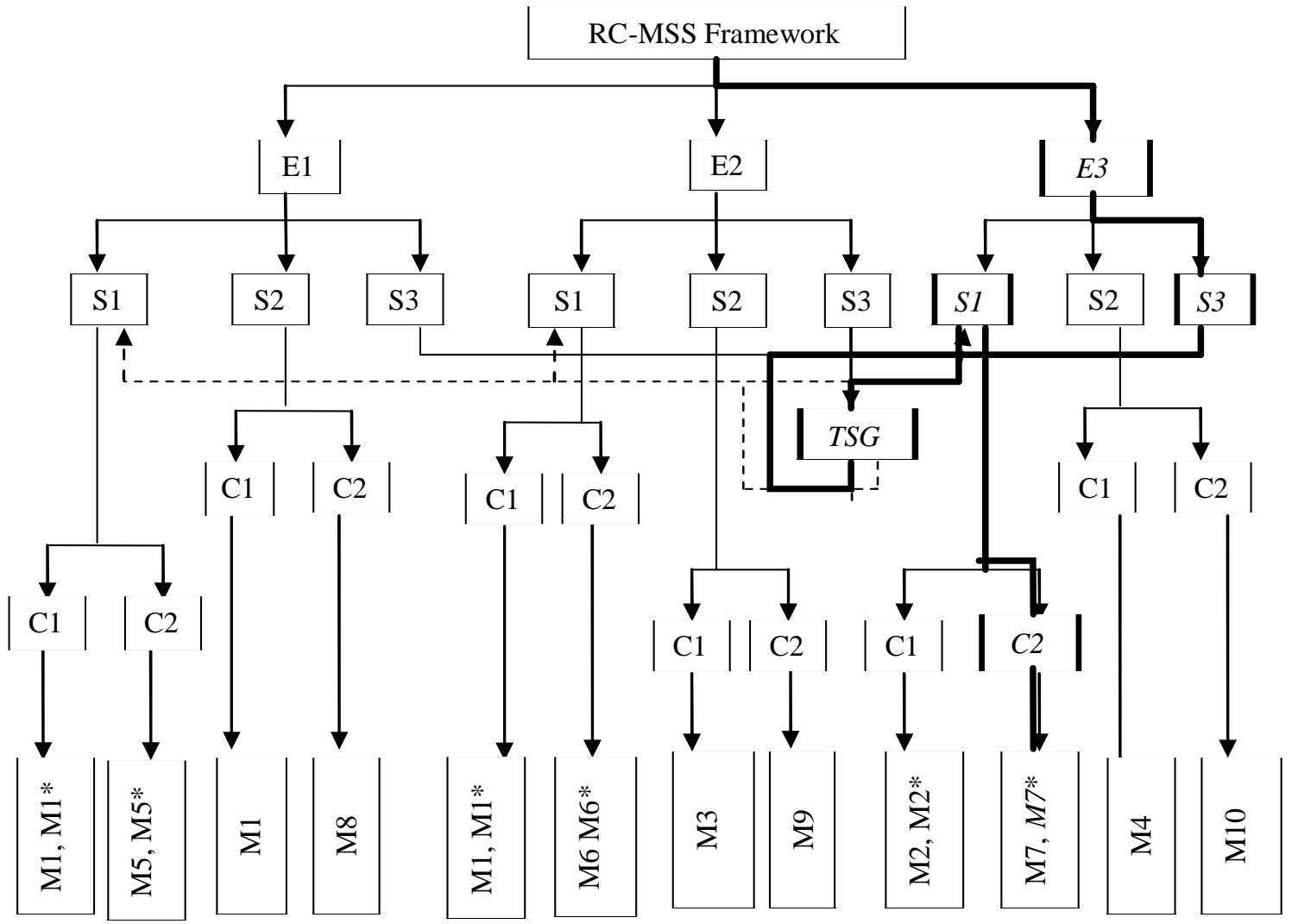

Note: Symbol ' $M$ ' denoted as materials suggested database, and * Represented material suggested database directed from the path from denoted symbol 'TSG'.

Figure 3. Direction path of design conditions to suggested materials database 
Every site condition was classified into each group as shown in Table 6. The geometric feature of the vertical gradient was non-critical while the horizontal curvature was critical. As mentioned earlier in Fig. 2, once either one of the geometric features of vertical gradient or horizontal curvature is denoted as ' $\mathrm{V} 2$ ' or 'H2', it would be considered as a critical region. Therefore, the example has been classified as symbol 'C2' of a critical area due to H2. Also the soil condition was classified as poor which was denoted by the symbol 'S3'. As discussed in the previous section of RC-MSS framework, the designer would enter the station denoted symbol 'TSG' then exit to station S1 before reaching the $7^{\text {th }}$ Asterisk "Material Suggested Database" denoted as symbol 'M7*'. The whole flow diagram is illustrated in Fig. 3, which is given a thicker plotted line. In the Asterisk "Materials Suggested Database", the database of pavement materials suggested for each layer would then refer to the flat terrain section denoted by symbol 'T1', except for the subgrade material which would be referred to the station denoted by symbol 'TSG'. The flow path can be illustrated in Fig. 4 and the suggested materials are summarized in Table 7. No rank is assigned to the database 'M7*' at 'T1', where these materials are equal in performance, durability and ease of construction under these site conditions. The results were analyzed using Friedman Statistical Method. Table 7present a summary of the data obtained for the example problem.

Table 6. Classification of design condition in example problem

\begin{tabular}{|c|c|c|}
\hline $\begin{array}{c}\text { Design } \\
\text { Condition }\end{array}$ & Classification & $\begin{array}{c}\text { Denoted } \\
\text { Symbol }\end{array}$ \\
\hline $\begin{array}{l}\text { Anticipated } \\
\text { ESAL }\end{array}$ & High & E3 \\
\hline Soil condition & Poor & S3 \\
\hline $\begin{array}{l}\text { Vertical } \\
\text { gradient }\end{array}$ & Non-critical & V1 \\
\hline $\begin{array}{l}\text { Horizontal } \\
\text { curvature }\end{array}$ & Critical & $\mathrm{H} 2$ \\
\hline Type of Terrain & Flat & T1 \\
\hline
\end{tabular}

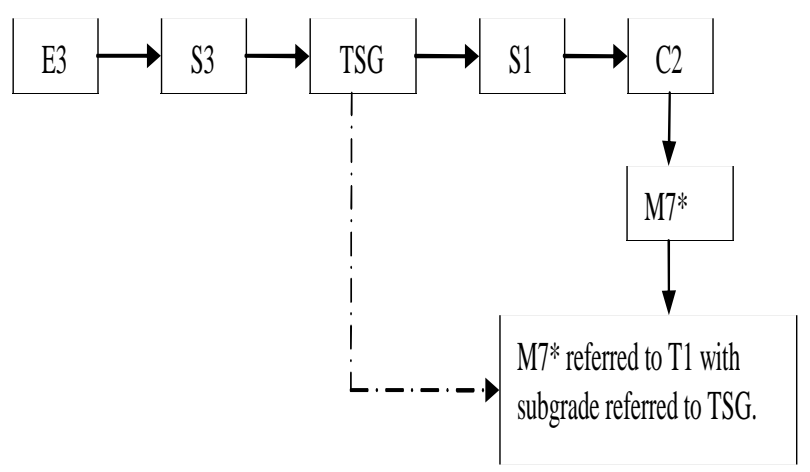

Figure 4. Whole flow path diagram in example problem
Table 7. Example problem summary using database 'M7*' and 'TSG' at 'T1'

\begin{tabular}{|c|c|c|c|c|}
\hline $\begin{array}{c}\text { Subgrade, } \\
\text { SG }\end{array}$ & $\begin{array}{c}\text { Subbase, } \\
\text { SB }\end{array}$ & $\begin{array}{c}\text { Base, } \\
\text { BC }\end{array}$ & $\begin{array}{l}\text { Binder, } \\
\text { SBC }\end{array}$ & $\begin{array}{l}\text { Surface, } \\
\text { SC }\end{array}$ \\
\hline Adopted & Type of & Type of & Type of & Type of \\
\hline Measured & Material & Material & Material & Materia \\
\hline Denoted & Denoted & Denoted & Denoted & Denoted \\
\hline $\begin{array}{c}\text { Symbol } \\
\text { (Positions) }\end{array}$ & Symbol & Symbol & Symbol & Syml \\
\hline TSG3 (1); & SB1 & BC1 & SBC & SC1 \\
\hline TSG5 (2); & SB1 & BC1 & SBC & SC2 \\
\hline TSG1 (3); & SB1 & BC1 & SBC & SC3 \\
\hline \multirow{2}{*}{$\begin{array}{c}\text { TSG2 (3), } \\
\text { and }\end{array}$} & SB1 & BC2 & SBC & SC1 \\
\hline & SB1 & BC2 & SBC & SC2 \\
\hline \multirow[t]{2}{*}{ TSG4 (3) } & SB1 & BC2 & SBC & SC3 \\
\hline & SB1 & BC4 & SBC & SC3 \\
\hline
\end{tabular}

\section{Development of a Prototype Expert System}

Microsoft Visual Basic 6.0 (VB6) was selected as a tool due to the simplicity of the program and its ability to provide a development of interface (Deitel, et al. 1999). The system framework was then translated into a numerical form or specific rule, which was incorporated into the development of an expert system of RC-MSS.

\subsection{Specific Rules}

Based on the data collected from the experts and documented information, the results of the studies were translated into seven sets of rules:

- Rule No.1: Designed Traffic Loading Volume (ESAL)

- $\quad$ Rule No. 2: Soil Condition

- $\quad$ Rule No. 3: Highly Stressed Area

- Rule No. 4: Type of Terrain

- $\quad$ Rule No. 5: Pavement Materials Suggested

- Rule No. 6: Pavement Material S elected

- $\quad$ Rule No. 7: Material Cost Calculation

The system start with the data available in Section Nos. 1, 2, 3 and 4 and use the inference rules. An inference engine searches the inference rules until it matches the ifclause which is known to be true. It concludes with the then-clause and the material suggested data available will determine which inference rules are used as shown in Section No. 5. Some data provide more than one material, so the user would select the material, and the selected one will display in Section No. 6. The user can also proceed to Section No. 7 for materials cost calculation for the selected ones. The inference rules in each category will be shown in each section as discussed below.

In Section 1, the designed traffic loading volume (ESAL), was divided into three categories, low, moderate and high, denoted as E1, E2 and E3, respectively. 


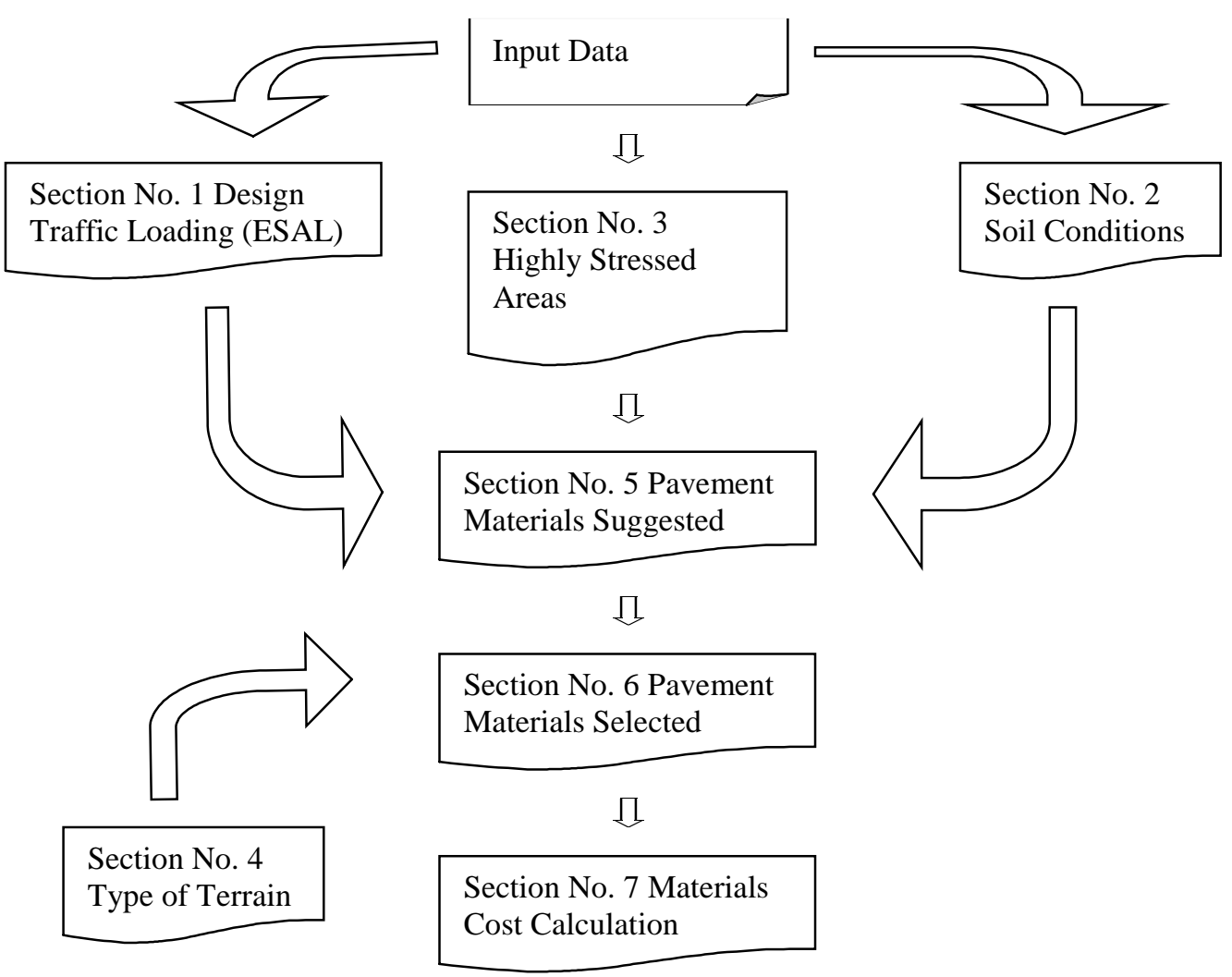

Figure 5. Rules sets

The Designed ESAL was converted into Expert System rules in the form as stated below:

Rule 1: If Designed ESAL $<300,000$, then the traffic volume is low (E1).

Rule 2: If Designed ESAL is between 300,000 and $10,000,000$, then the traffic volume is moderate (E2).

Rule 3: If Designed ESAL $>10,000,000$, then the traffic volume is high (E3).

The soil conditions in Section 2 is based on CBR values. From framework RC-MSS, CBR values were divided into three categories: good, fair and poor soils. Each of the categories are given symbols S1, S2, and S3, respectively. The CBR value is then converted into three rules. The three rules are:

Rule 1: If CBR $>10 \%$, then the soil is Good (S1).

Rule 2: If CBR value is more than $5 \%$ and less than 10 $\%$, then the soil is Fair (S2).

Rule 3: If CBR $<5 \%$, then the soil is poor (S3).

Highly stressed areas (Section 3) are divided into two groups, which are vertical gradient and horizontal curve (refer to Table 3). Each of these groups is further divided into two conditions: highly stressed and not highly stressed regions. V1 and $\mathrm{H} 1$ represent the symbol of non highly-stressed areas and V2 and $\mathrm{H} 2$ represent the symbols of highly-stressed areas for vertical gradient and horizontal curve, respectively.

Two rules were used in defining vertical gradient conditions as shown below:

Rule 1: If Vertical Gradient $<5 \%$, then it is a NonHighly Stressed Area (V1).

Rule 2: If Vertical Gradient $\geq 5 \%$, then it is a Highly Stressed Area (V2).

Similar to vertical gradient, horizontal curve was also divided into two rules as presented below:

Rule 1: If Horizontal Curvature $<7^{\circ}$, then it is a NonHighly Stressed Area (H1).

Rule 2: If Horizontal Curvature $\geq 7^{\circ}$, then it is a Highly Stressed Area (H2).

The two stressed area conditions are then combined and converted into four combinations of rules. The four rules are: 
The Journal of Engineering Research Vol. 4, No.1 (2007) 1-10

Rule 1: If Vertical Gradient is V1 and Horizontal Curvature is H1, then it is Non-Highly Stressed Area which is C1.

Rule 2: If Vertical Gradient is V1 and Horizontal Curvature is H2, then it is a Highly Stressed Area which is $\mathrm{C} 2$.

Rule 3: If Vertical Gradient is V2 and Horizontal Curve is $\mathrm{H} 1$, then it is a Highly Stressed Area which is C2.

Rule 4: If Vertical Gradient is V2 and Horizontal Curve is $\mathrm{H} 2$, then it is a Highly Stressed Area which is C2.

Type of terrain in Section 4 is divided into three types: flat, rolling and mountainous as follows:

Rule 1: If a Flat Terrain is selected, then it is defined as T1.

Rule 2: If a Rolling Terrain is selected, then it is defined as T2.

Rule 3: If a Mountainous Terrain is selected, then it is defined as T3.

Once the four rules are selected, matching of each rule under particular design conditions would then be entered to match the database stored in Microsoft Access 2000 as shown in Section 5.

The matched design conditions to the particular database of suggested pavement materials would then be extracted as mentioned in Section 3, which is Suggested Materials. When the desired material is selected, material ranking would then be displayed in the form as shown in Section 6.

The last section of materials cost calculation (Section 7) is an optional part, in case the user wants the system to calculate the materials cost for the selected pavement materials in each layer used in a particular project.

\subsection{Databases}

The database is the place where all the data are recorded and kept in the expert system. The reasons for setting databases are to store huge data into an inventory and to facilitate its use for future references; checking the findings of the ES; editing data; updating; adding; or even deleting the data.

\subsection{Development of RC-MSS}

RC-MSS was developed into an expert system, ES, for a pavement materials selection system. It was compiled and executed from an executable file. Figure 6 shows the flow chart of RC-MSS. It is currently a first version road materials selection system (RC-MSS) for a new flexible pavement construction. The major task in building the knowledge-based system is to acquire and encode the expertise and knowledge of experts into the knowledgebase.

RC-MSS consists of two main components: the RCMSS VB6.0 file and RC-MSS Database file. The first component was the system rules, preset commands and rule execution to reach the database. It is the shell of the system. RC-MSS database file is located in Microsoft
Access 2000. This program can associate with VB6.0 where both programs operate under a Microsoft Operating System. All the materials suggested in addition to the matching group from the input (design data) would be stored in RC-MSS database file.

\section{Output Result: Suggested Pavement Materials and Selected Pavement Materials}

Once the input data information are completed, the specific rules in each input data would be sorted by an inference engine to match the knowledge-base. The process is similar to the framework of the RC-MSS shown in the Fig. 3. Some suggested materials were ranked by the system to show the difference in performance in that particular input data condition. Figure 6b in Appendix II shows the selected pavement materials by the user.

\section{Materials Costs Calculation}

RC-MSS also provides a rough overall materials costs calculation for the selected pavement materials. The accumulated materials costs would be displayed after every input icon is entered as presented in Fig. 6d in Appendix II. The description of each interface is presented in Table 8.

Table 8. Figures 6a to 6d description in Appendix II

\begin{tabular}{|c|c|}
\hline $\begin{array}{l}\text { Figure } \\
\text { No. } \\
\text { 6a }\end{array}$ & \begin{tabular}{l}
\multicolumn{1}{c}{ Figure } \\
File \\
RC-MSS \\
data input \\
diagram \\
(geometric \\
design and \\
traffic \\
estimation)
\end{tabular} \\
\hline 6b & $\begin{array}{l}\text { RC-MSS } \\
\text { suggested } \\
\text { pavement } \\
\text { materials }\end{array}$ \\
\hline
\end{tabular}

$6 c$

RC-MSS selected pavement materials

$6 d$

RC-MSS materials cost calculation

\section{Description}

Input data of design conditions. The Input data consist of :

1.Estimated traffic loading (ESAL),

2.Geometric feature of vertical gradient and horizontal curvature,

3. Type of terrain, and

4. Soil CBR.

Output of the suggested pavement materials extract from Microsoft Access 2000 for matched rules.

Figure $6 \mathrm{~b}$ shows the suggested pavement and the soil CBR is more than $5 \%$.

The selected pavement materials would display in this form and material description button would show the selected material description.

Input icon of layer thickness and cost of materials needed to enter before each layer materials and the total material cost can be calculated. 


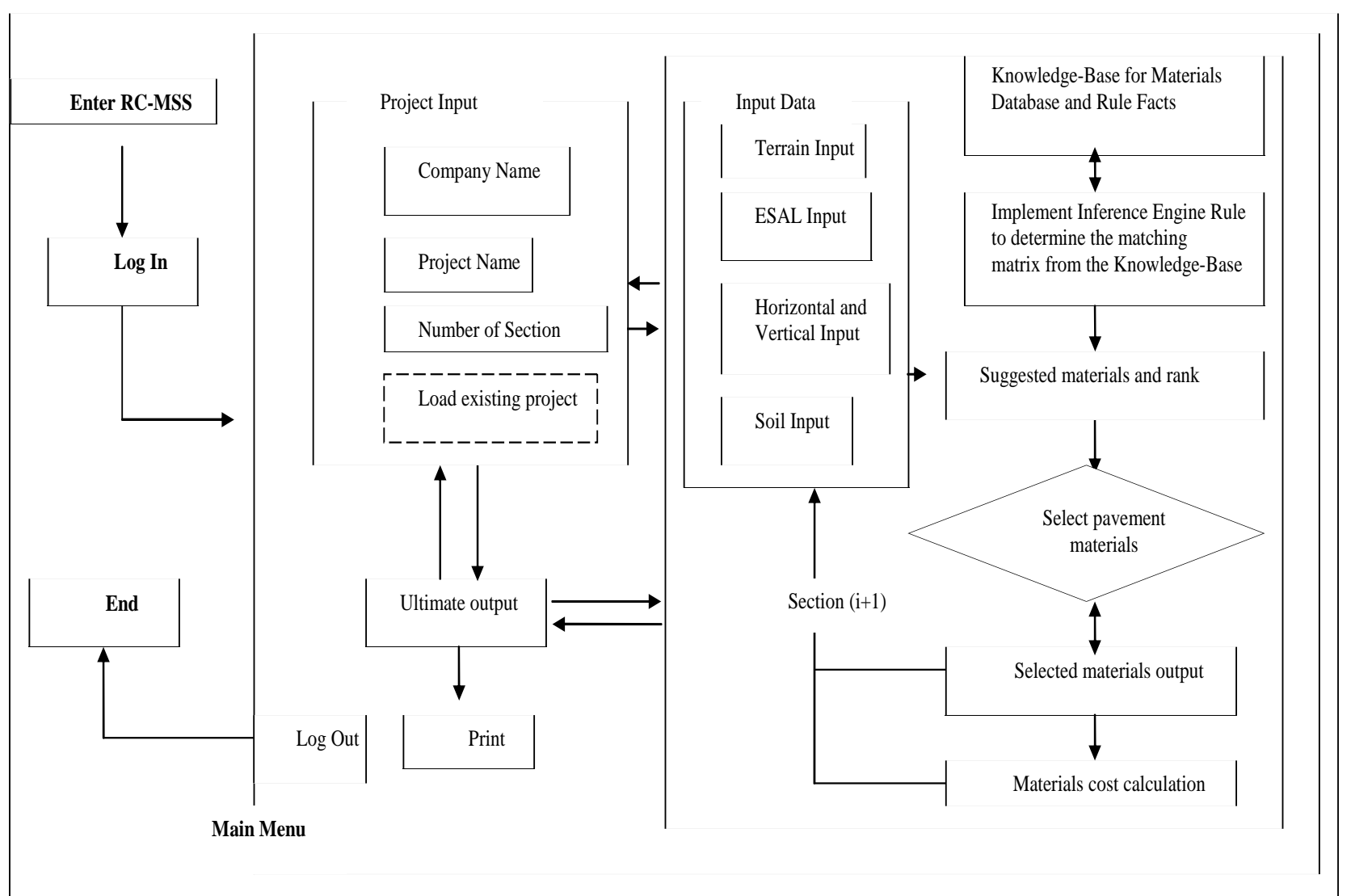

Figure 6. Hierarchy of an expert system in road construction materials system (RC-MSS)

\section{Conclusions}

With this prototype development of a pavement materials selection system, the road designer is more likely to view more proper pavement materials alternatives in the initial stage of materials selection. Moreover, the system is easy to use and a brief cost materials calculation could be done via this RC-MSS. With this system, the road designer has more materials choices and it is not necessary only to stick to a dense-graded mixture of asphalt concrete. Since this is a prototype material selection system, a comprehensive system is needed which comprises the mechanistic-design method. Further investigations of weather effect on materials properties would make the database of the system more effective, valid, precise and reliable.

\section{Acknowledgments}

We would like to acknowledge the funding provided by the Ministry of Science, Technology and Environment, Malaysia. We would also like to show appreciation to those road design engineers and pavement experts who helped in data collection and analysis.

\section{References}

Deitel, H.M., Deitel, P.J. and Nieto, T.R., 1999, "Visual
Basic 6: How to Program," New Jersey: Prentice Hall. Emby, J. and Mustafa, M.S., 1996, "The Quality of Asphaltic Concrete Mixes in Malaysia," Proceeding of the Second Malaysia Road Conference, 2nd MRC Malaysian Road Conference.

Goh, A.T.C., 1993, "Advisory Expert System for Flexible Pavement Design," Artificial Intelligent in Engineering 0954 - 1810/93/506.00, Vol. 8, pp. 47 56. Elsevier Science Publishers Ltd.

Harun, M.H., 1992, "The Performance of Various Bitumen Modifiers on Climbing Lanes," JKR, Mesyuarat Penolong Pengarah Jalan 3/92. Kuala Lumpur: Public Work Department.

Huang, Y.H., 1993, "Pavement Analysis and Design," New Jersey: Prentice-Hall.

JKR, 1986, "A Guide On Geometric Design of Roads," Arahan Teknik (Jalan) 8/86. Kuala Lumpur: Public Work Department.

Lay, M.G., 1990, "Transportation Studies Volume 8," Handbook of Road Technology (2nd ed.) Vol. 1, Planning and Pavements.

Muniandy, R., Vasudevan, J. and Omar, H., 2002, "Laboratory Evaluation of Malaysian Cellulose Oil Palm Fiber for use in Stne Mastic Asphalt Mixes," International Journal of Pavements, Vol. 1(3), pp. 13 21.

Omar, H., 200, "Development of Expert Systems," Qualifying Exam, UPM, Seri Kembangan. 
The Journal of Engineering Research Vol. 4, No.1 (2007) 1-10

\section{Appendix I Road Construction Material Selection System (RC-MSS) Database}

Denoted Symbol as TSG

SITE CONDITION 10: Soil=Poor (CBR <5\%), regardless of traffic loading and critical area.

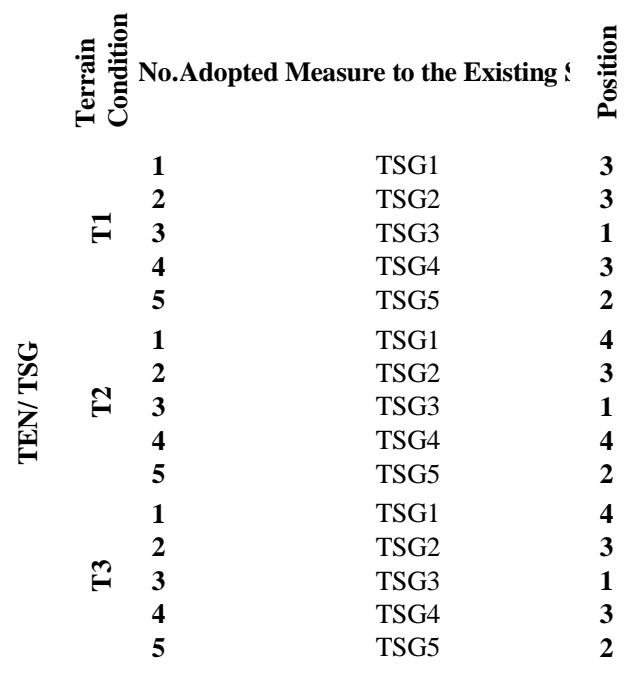

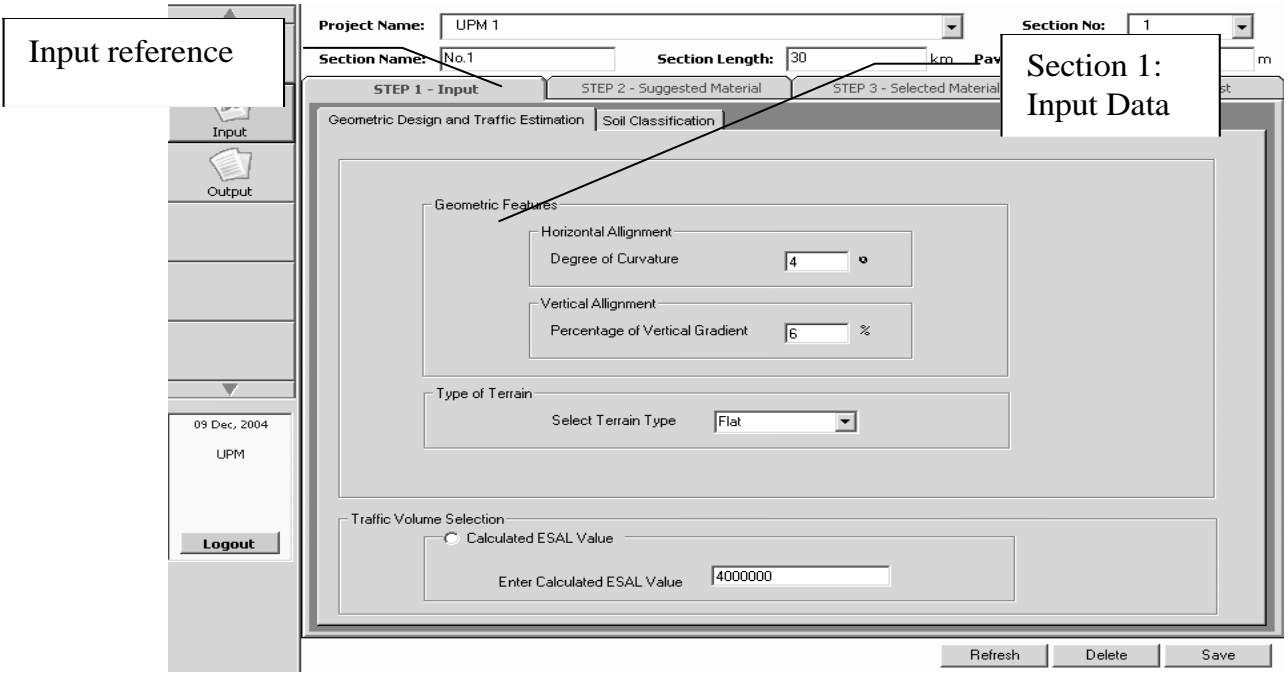

Figure 6a. RC-MSS data input diagram (geometric design and traffic estimation)

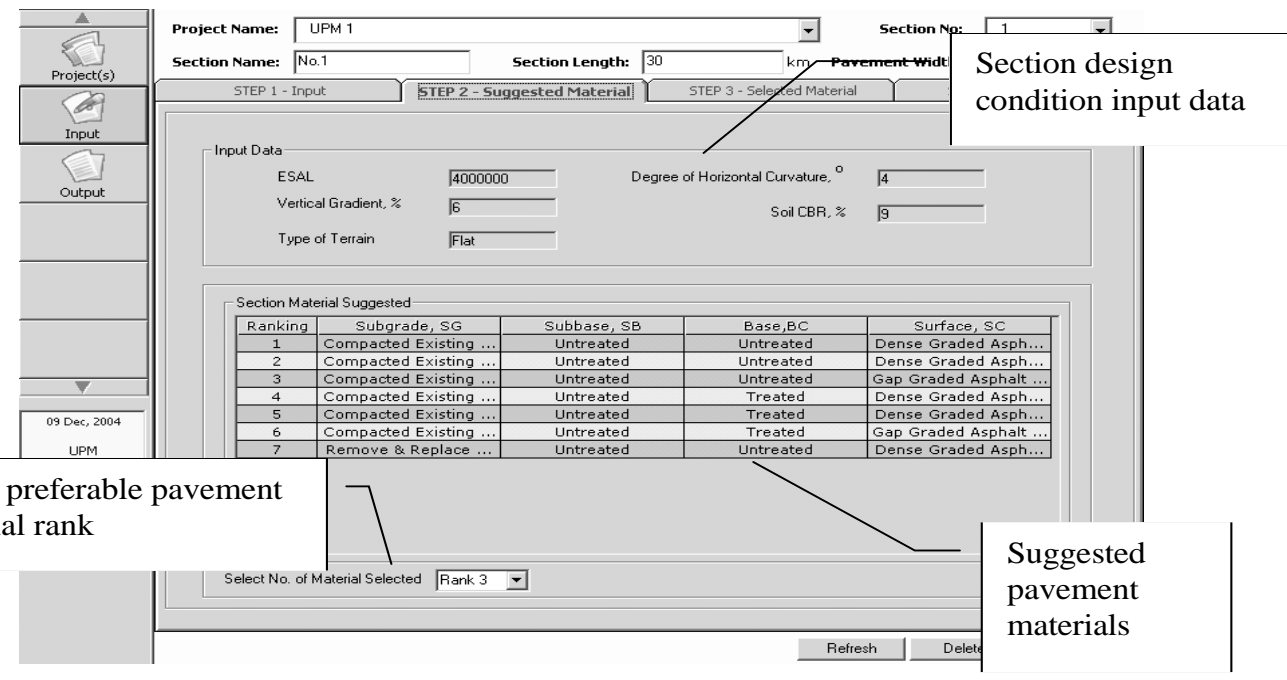

Figure 6b. RC-MSS suggested pavement materials 


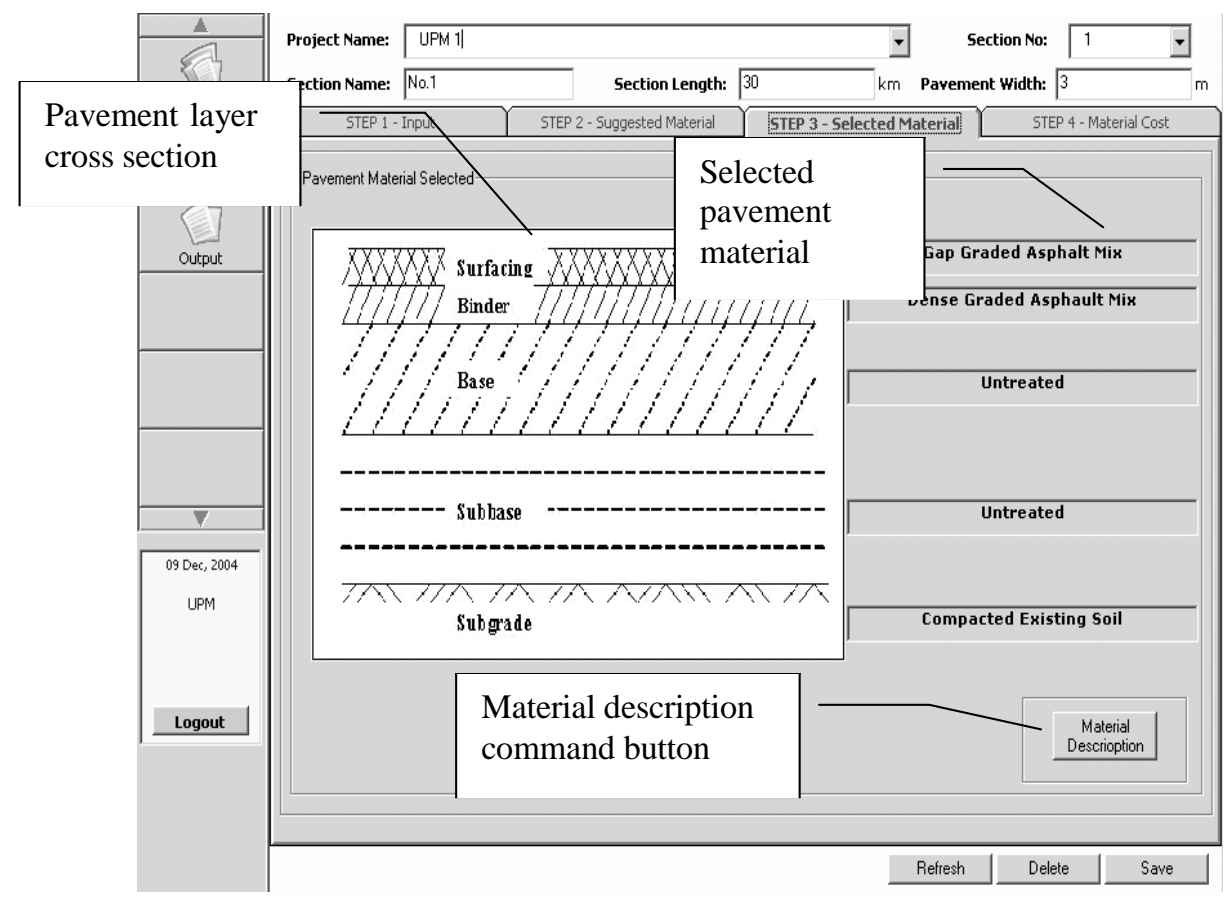

Figure 6c. RC-MSS selected pavement material

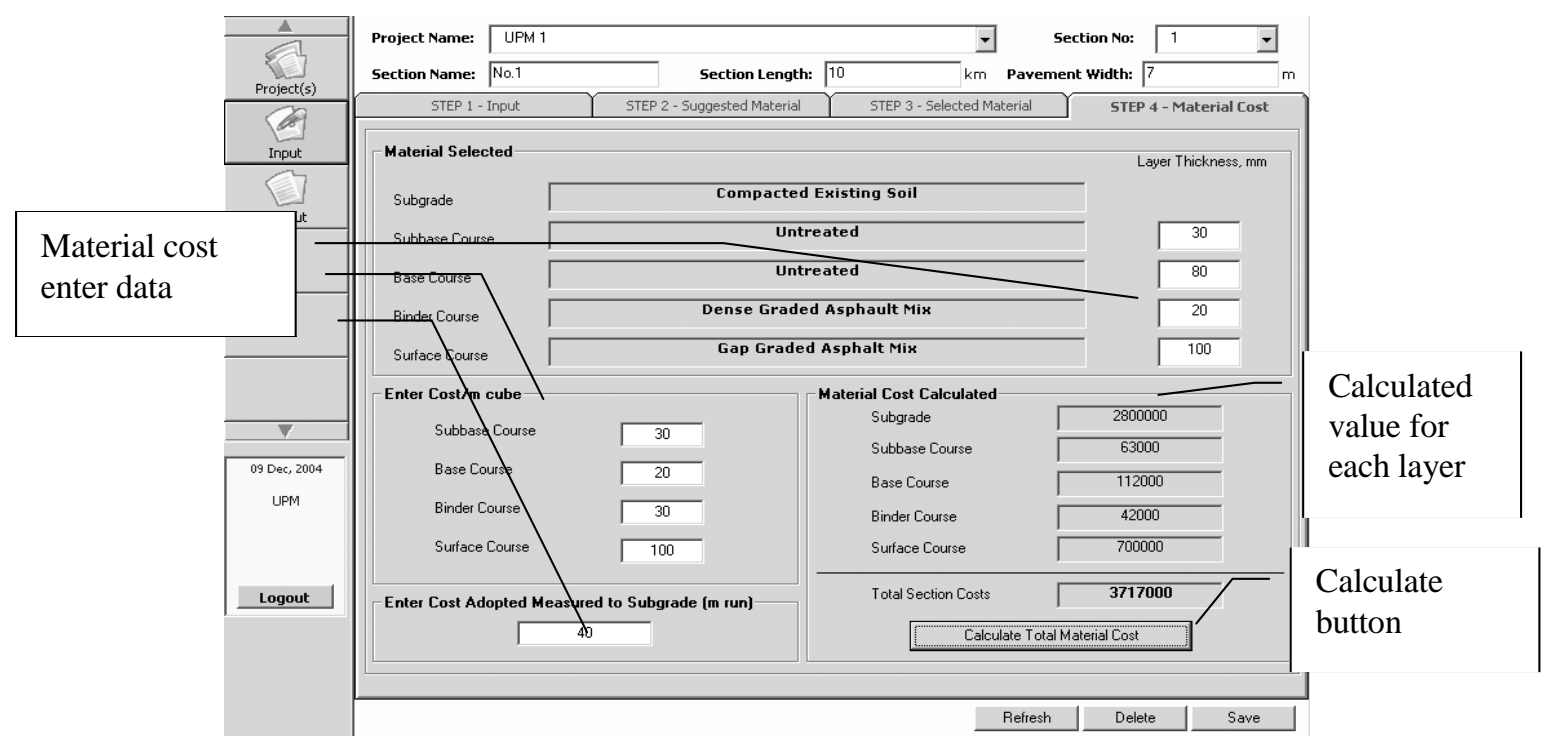

Figure 6d. RC-MSS materials cost calculation 